\title{
Characterization of seismic signals recorded in Tethys Bay, Victoria Land (Antarctica): data from atmosphere-cryosphere-hydrosphere interaction
}

\author{
Andrea Cannata ${ }^{1,2^{*}}$, Graziano Larocca ${ }^{2}$, Paola Del Carlo ${ }^{3}$, Gaetano Giudice ${ }^{4}$, \\ Giovanni Giuffrida ${ }^{4}$, Marco Liuzzo $^{4}$, Luciano Zuccarello² ${ }^{2}$, Giuseppe Di Grazia ${ }^{2}$, \\ Salvatore Gambino ${ }^{2}$, Eugenio Privitera ${ }^{2}$, Alberto Delladio ${ }^{5}$, Paolo Grigioni ${ }^{6}$ \\ ${ }^{1}$ Università degli Studi di Perugia, Dipartimento di Fisica e Geologia, Perugia, Italy \\ ${ }^{2}$ Istituto Nazionale di Geofisica e Vulcanologia, Osservatorio Etneo-Sezione di Catania, Catania, Italy \\ ${ }^{3}$ Istituto Nazionale di Geofisica e Vulcanologia, Sezione di Pisa, Pisa, Italy \\ ${ }^{4}$ Istituto Nazionale di Geofisica e Vulcanologia, Sezione di Palermo, Palermo, Italy \\ ${ }^{5}$ Istituto Nazionale di Geofisica e Vulcanologia, Sezione di Roma, Roma, Italy \\ ${ }^{6}$ ENEA, Laboratory for Observation and analyses of Earth Climate (SSPT-PROTER-OAC), Roma, Italy
}

\section{Article history}

Received March 9, 2017; accepted July 2, 2017.

Subject classification:

Microseisms, Meteorological parameters, Icequakes, Antarctica.

\begin{abstract}
In this paper, we analysed 3-component seismic signals recorded during 27 November 2016 - 10 January 2017 by two stations installed in Tethys Bay (Victoria Land, Antarctica), close to Mario Zucchelli Station. Due to the low noise levels, it was possible to identify three different kinds of signals: teleseismic earthquakes, microseisms, and icequakes. We focus on the latter two. A statistically significant relationship was found between microseism amplitude and both wind speed and sea swell. Thus, we suggest that the recorded microseism data are caused by waves at the shore close to the seismic stations rather than in the deep ocean during storms. In addition, we detected three icequakes, with dominant low frequencies (below $2 \mathrm{~Hz}$ ), located in the David Glacier area with local magnitude of 2.4-2.6. These events were likely to have been generated at the rock-ice interface under the glacier. This work shows how seismic signals recorded in Antarctica provide insights on the interactions between the atmosphere-cryosphere-hydrosphere. Since climate patterns drive these interactions, investigations on Antarctic seismic signals could serve as a proxy indicator for estimating climate changes.
\end{abstract}

\section{Introduction}

It is now clear that seismic signals from continuously recording broadband seismic stations contain information beyond tectonic earthquake sources and the Earth's structure. These records include microseism energy and icequakes.
The Earth is not static but constantly vibrating due to many continuous noise sources such as ocean waves, storms and anthropic activities [e.g. Brenguier et al. 2016]. The most continuous and ubiquitous seismic signal on Earth is microseisms, mainly composed of surface waves and closely related to ocean wave energy coupling with the Earth's motion [e.g. Aster et al. 2008, Ferretti et al. 2013, Pratt et al. 2017]. Two types of microseisms are generally distinguished: primary and secondary. The former is generated by direct ocean waves in the shallow seafloor interacting with the sloping seafloor, by breaking or shoaling [e.g. Hasselmann 1963, Grob et al. 2011]. This seismic signal has the same period as the generating ocean waves [10-20 s; Hasselmann 1963]. Secondary microseisms are more energetic and are generated by standing or colliding waves within the ocean wave field near the coast or in the deep ocean, and have shorter periods (3-10 s; Grob et al. 2011, and references herein). Because of their source, microseisms can be used to make inferences on climate changes [e.g. Grevemeyer et al. 2000, Anthony et al. 2015].

Icequakes are defined as coseismic brittle fracture events within the ice [e.g. Podolskiy and Walter 2016] or, more generally, are seismic events associated with ice dynamics. Many processes can lead to the nucleation of icequakes such as near surface crevassing, 
iceberg calving, stick-slip motion [e.g. Podolskiy and Walter 2016]. From the analysis of icequakes, new light has been shed on phenomena such as iceberg calving, glacier and sea ice dynamics [e.g. Podolskiy and Walter 2016, and references therein].

Thanks to the complete lack of anthropic noise, Antarctica can be considered a perfect natural laboratory to investigate microseisms and icequakes. In this work, we analyse the seismic signals recorded in Tethys Bay (Victoria Land), close to the Italian station Mario Zucchelli, during the XXXII Italian expedition in Antarctica.

\section{Seismic data}

Seismic data were acquired by 2 temporary stations (called STN01 and STN02) installed at about 950 $\mathrm{m}$ apart nearby Tethys Bay, close to the Italian Mario Zucchelli Station (MZS), from 27 November 2016 to
10 January 2017 (see Table 1 for coordinates and Figure 1). The stations were equipped with Nanometrics Trillium 120s Compact, that sampled ground velocity at a rate of $100 \mathrm{~Hz}$.

In order to characterise the seismicity of the area, seismograms containing both long (from 1 hour to the whole investigated interval) and short (from a few tens of seconds to 1 hour) periods were visualised and inspected. Three different kinds of seismic signals can be recognised (Figure 2): (i) long-lasting tremor-like signals, (ii) long-lasting transients, (iii) short duration transients.

\begin{tabular}{lcc}
\hline & $\begin{array}{c}\text { Latitude } \\
\left({ }^{\circ} \mathrm{N} \text { WGS84 }\right)\end{array}$ & $\begin{array}{c}\text { Longitude } \\
\left({ }^{\circ} \mathrm{E} \text { WGS84 }\right)\end{array}$ \\
\hline STN01 & -74.70249 & 164.05978 \\
STN02 & -74.69803 & 164.08647 \\
\hline
\end{tabular}

Table 1. Coordinates of the stations installed nearby Tethys Bay.
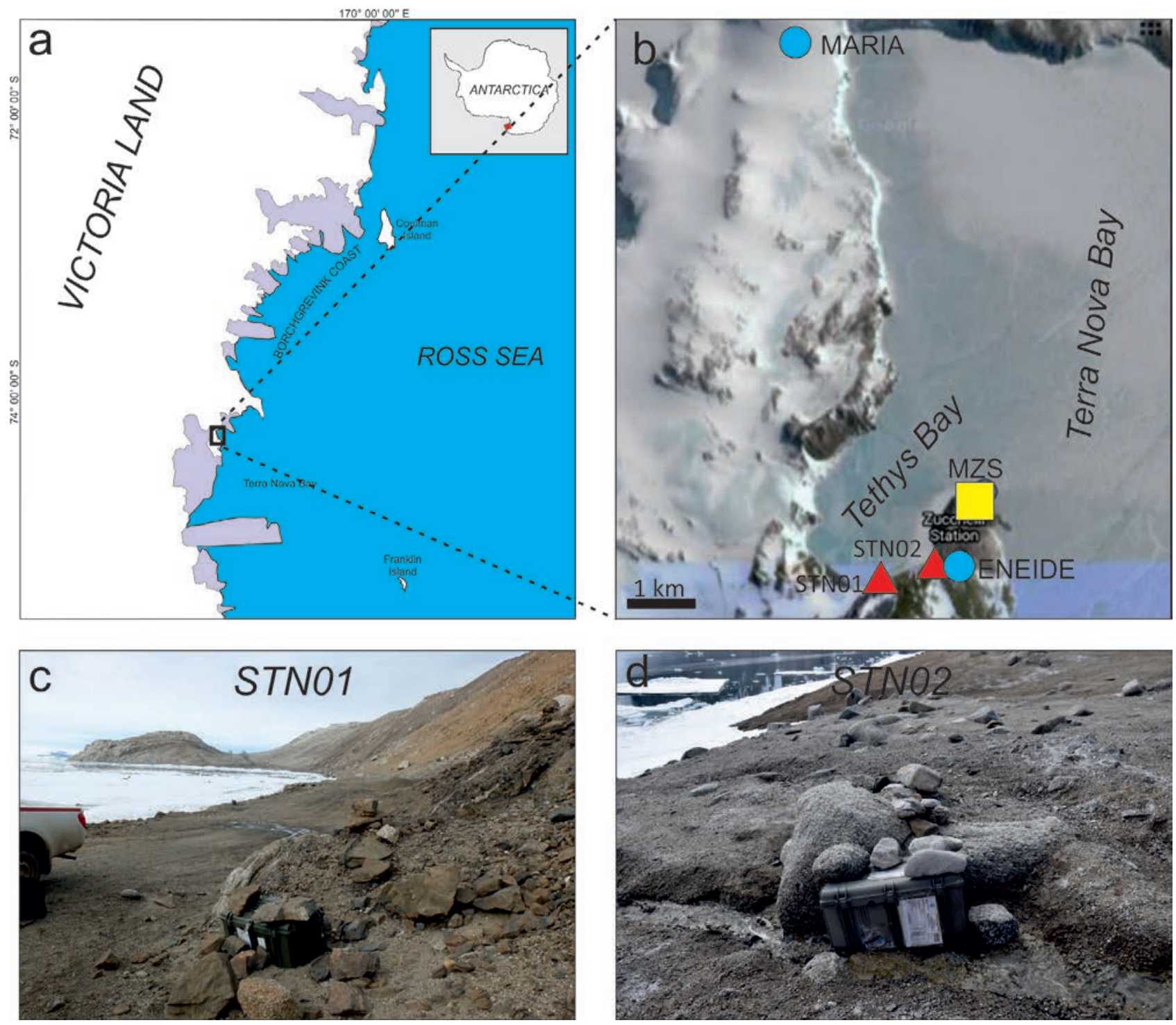

Figure 1. (a) Map of Victoria Land. (b) Aerial image of Tethys Bay from Google Earth with the locations of seismic stations (triangles), meteorological stations (circles) and Mario Zucchelli Station (MZS, square). (c,d) Pictures of installations of the seismic stations STN01 and STN02, respectively (credits Graziano Larocca; (C) PNRA). 

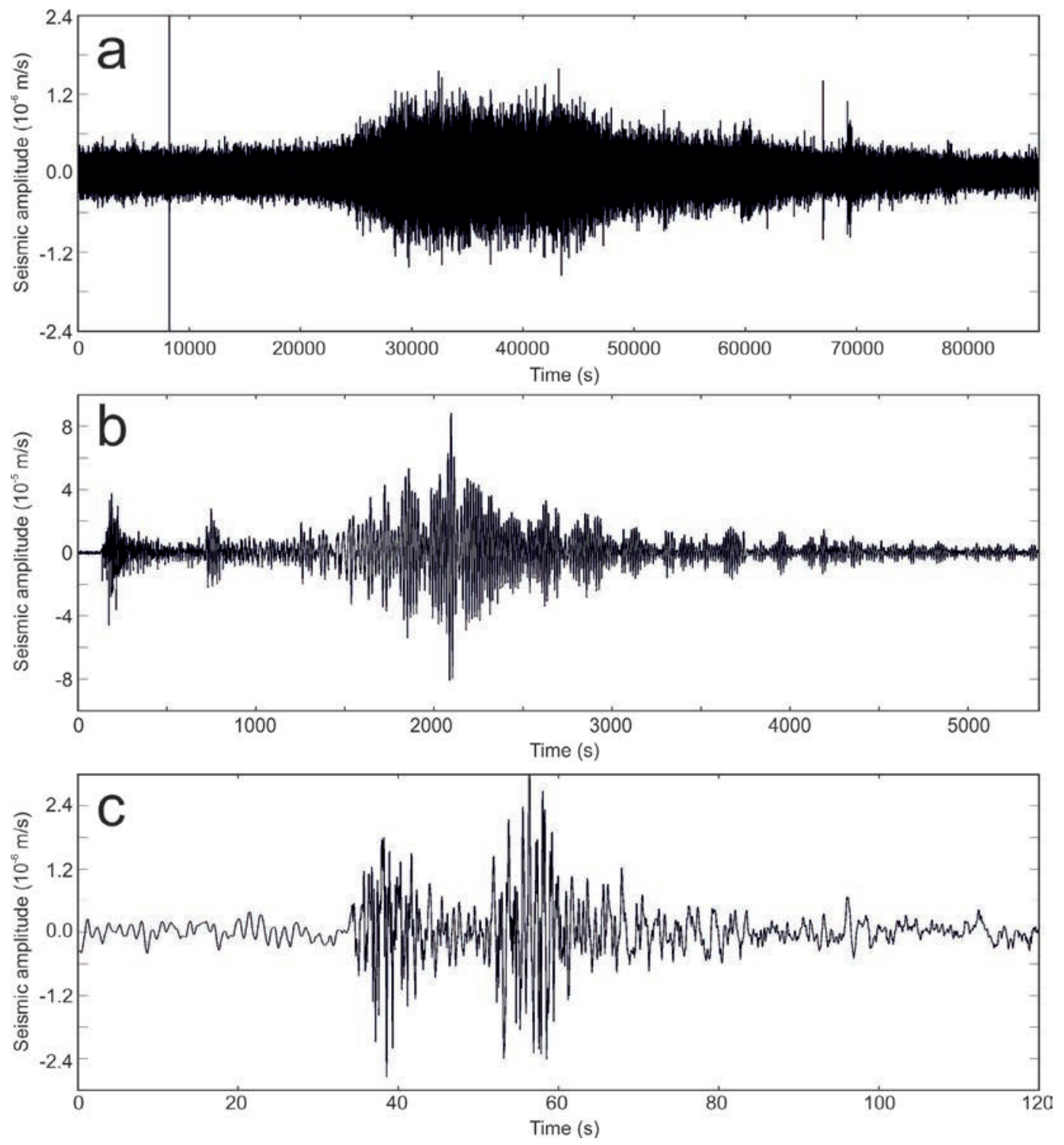

Figure 2. Examples of long-lasting tremor-like signals (a), long-lasting transients (b), short duration transients (c), recorded by the vertical component of STN01 station.

Signals of type (i) appear to be similar to seismic tremor [volcanic or non-volcanic in origin; e.g. McNutt 2005, Beroza and Ide 2011], with emergent onset and tail, amplitude gradually changing within time intervals of several hours, and frequency content below $1.5 \mathrm{~Hz}$ (Figure 2a). Signals of type (ii) are seismic events with duration of tens of minutes to hours and most energy lower than $0.5 \mathrm{~Hz}$ (Figure $2 \mathrm{~b}$ ). These are teleseismic events, associated with distant and strong earthquakes. Lastly, signals of type (iii) are short transients with duration of 20-30 s, and frequency lower than $2 \mathrm{~Hz}$ (Figure 2c). In this work, we analyse types (i) and (iii) separately.

\subsection{Long-lasting tremor-like signals}

The signals of type (i) persisted over a period of several hours to a few days with gradually changing amplitude, and a frequency content mostly below $2 \mathrm{~Hz}$.
We calculated spectrograms in order to examine the frequency character of the signal. The spectra were calculated from consecutive 163.84-second-long signal windows (containing $2^{14}$ samples). Each segment was Hanning-windowed to reduce spectral leakage. All spectra from within a 30-minute period were averaged and are displayed in Figure 3. There are two bands of high spectral amplitudes, $<0.25 \mathrm{~Hz}$ and between 0.25 and $1.50 \mathrm{~Hz}$, corresponding to classical microseism frequency content [e.g. Grob et al. 2011]. We calculated the root mean square (RMS) amplitude in both the bands (Figure 4).

The energy at $<0.25 \mathrm{~Hz}$ is relatively constant, but with isolated periods of high amplitude (29/11/2016 01/12/2016, 06/12/2016 - 08/12/2016, 15/12/2016 - 16/12/2016 and 04/01/2017 - 09/01/2017). The energy in the $0.25-1.50 \mathrm{~Hz}$ band is more variable, with maxima during 29/11/2016 - 01/12/2016, 14/12/2016 $-18 / 12 / 2016$ and $04 / 01 / 2017-09 / 01 / 2017$. 


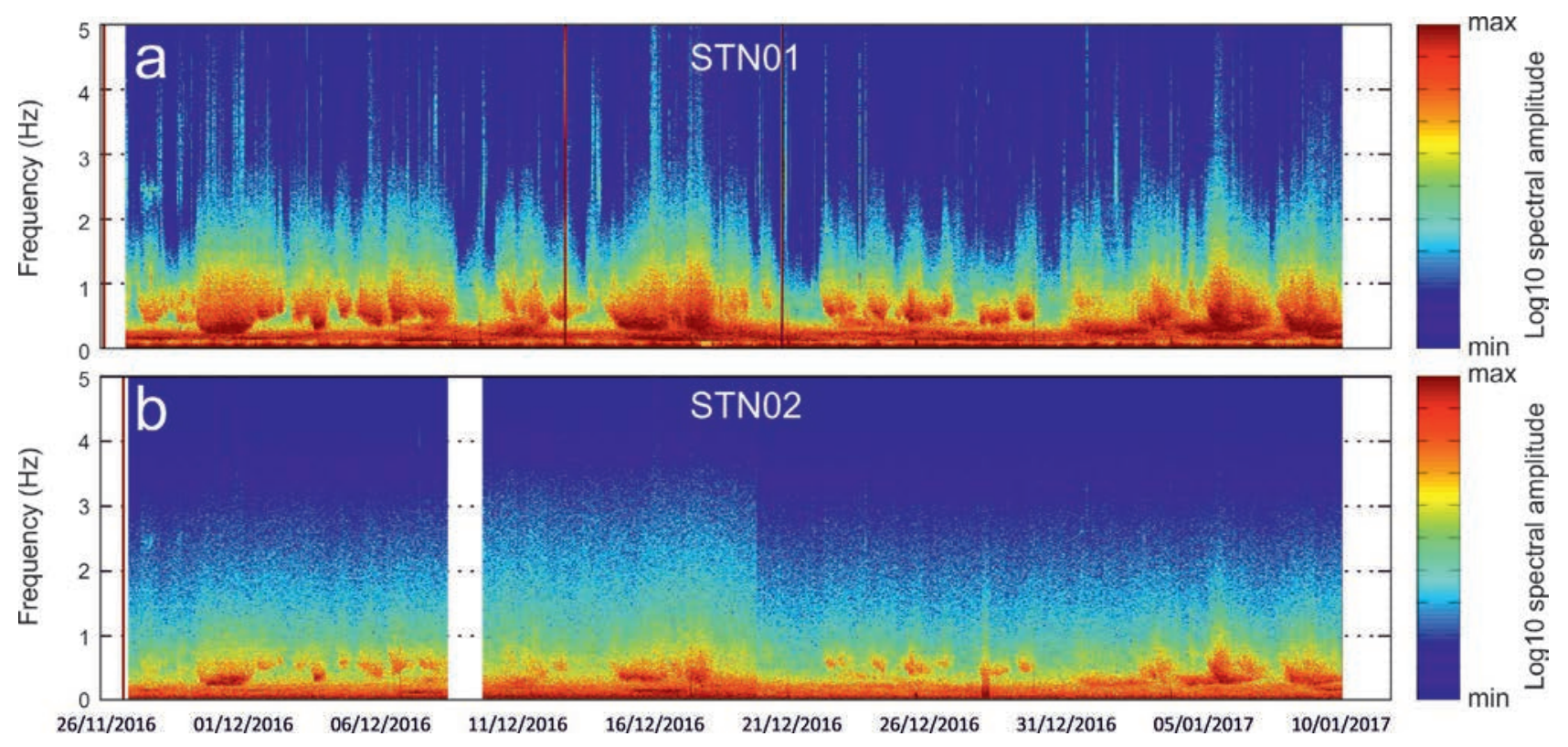

Figure 3. Spectrograms of the vertical component of STN01 (a) and STN02 (b) in the band 0-5 Hz.

In order to investigate the relationship of these two low frequency bands with meteorological parameters, we compared them with the wind speed, acquired at 1 minute sampling intervals by two stations located in Terra Nova area, called "Eneide" and "Maria" (circles in Figure 1b; wind speed data and information were obtained from 'Meteo-Climatological Observatory' of PNRA - www.climantartide.it). In addition, we also took into account the data of sea swells in the coast close to MZS, provided by the Ufficio Meteorologico of MZS; such information, recorded three times per day (at 7:00, 13:00 and 19:00 MZS time, UTC +13 hours), is qualitative
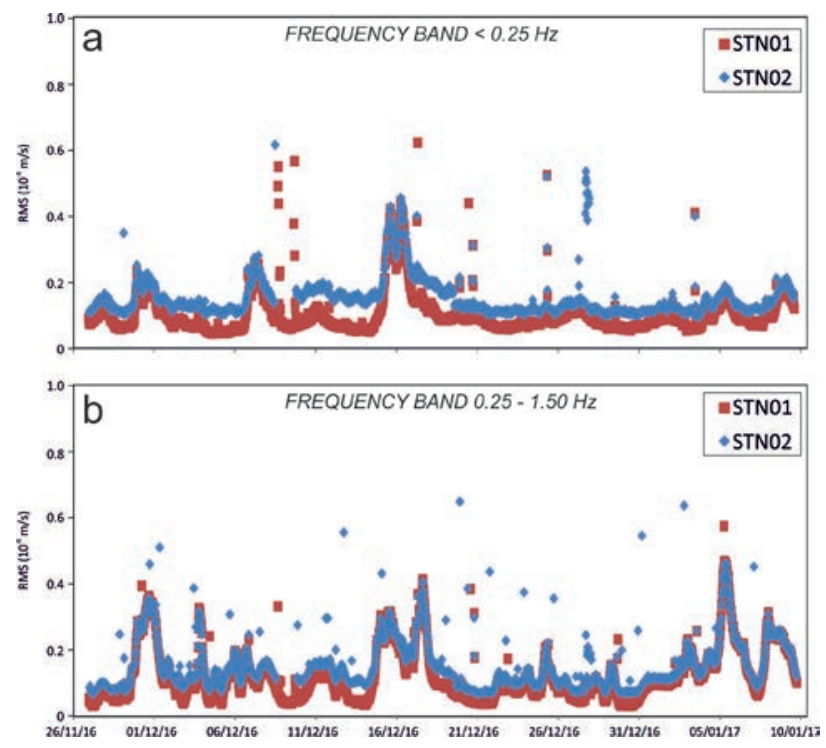

Figure 4. RMS of the vertical component of the signals recorded by STN01 (red squares) and STN02 (blue diamonds) in the bands $<0.25$ (a) and $0.25-1.50 \mathrm{~Hz}$ (b). and starts at the end of December when the sea ice melts at MZS. All the meteorological time series are shown in Figure 5. In order to estimate a quantitative relationship between environmental parameters and microseisms, we used two techniques: wavelet transform coherence (WTC) and randomised cross correlation (RCC). To compare seismic RMS amplitude and wind speed, both the time series were resampled at 30 minutes intervals. Because of the lower sampling rate of sea swells, to compare seismic RMS amplitude and sea swells, both the time series were resampled at 3-hour intervals. The seismic RMS of STN01 was used because it showed no data gaps.

WTC is a method by which the covariance of two signals can be examined in both time and frequency domains. The method provides information on the phase relationship between time series [e.g. Torrence and Compo 1998, Grinsted et al. 2004]. Comparisons between time series by WTC have been performed in seismology [e.g. Cannata et al. 2010, 2013], as well as in other disciplines such as epidemiology [e.g. Yang et al. 2008], meteorology (e.g. Jevrejeva et al. 2003] and astrophysics [e.g. Donner and Thiel 2007]. With respect to the widely used Pearson's correlation coefficient, WTC has the ability to provide information not only in the time but also in the frequency domain at different observation scales. The wavelet transform suffers from edge artefacts, hence it is useful to introduce a cone of influence (COI) in which edge effects cannot be ignored. Finally, also the disturbances affecting the considered time series have to be taken into account. Geophysical time series are commonly characterized by increasing disturbances 

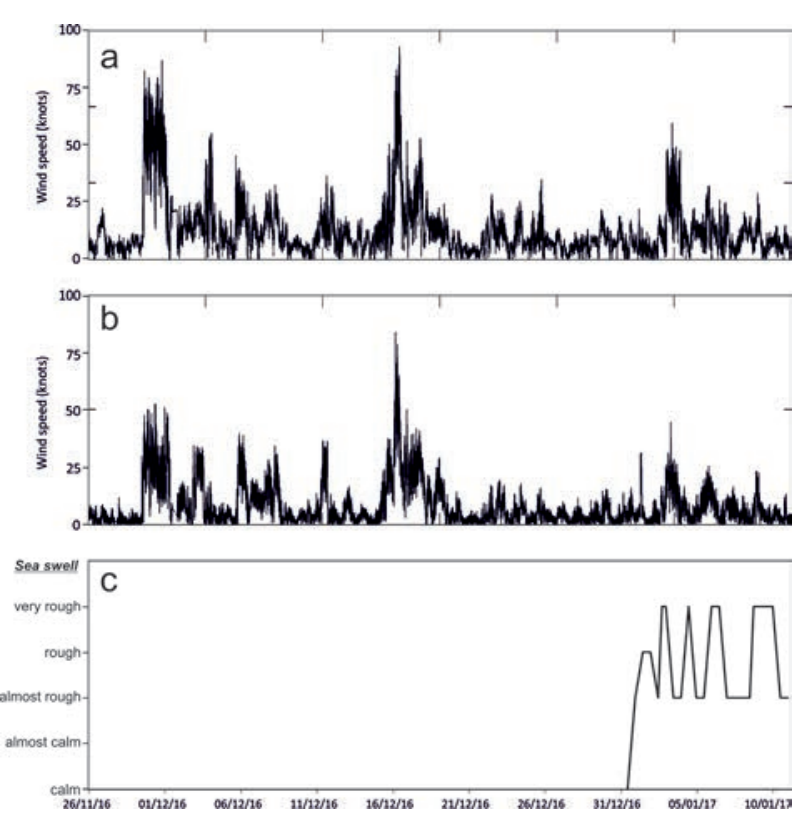

Figure 5. (a) Wind speed at Maria meteorological station, (b) wind speed at Eneide meteorological station, (c) sea swell conditions. Wind speed data were provided by 'Meteo-Climatological Observatory' of PNRA (http:/ / www.climantartide.it), and sea swell information by Ufficio Meteorologico of MZS.

at lower frequencies and show many distinctive features of red noise (that is, higher noise amplitudes at lower frequencies). Following previous studies [e.g. Grinsted et al. 2004, Jevrejeva et al. 2003], a 5\% statistical significance level against red noise is considered in this work.

The RCC method is used to determine whether the correlations between two time series (in our case, seismic RMS and meteorological time series) is statistically significant or if it may be due to chance. To do so, we calculated the correlation 1,000 times, randomizing at each run the times of the meteorological time series. Following Saccorotti and Del Pezzo [2000], Martini et al. [2009] and Zuccarello et al. [2013], to calculate mean and standard deviation of the randomized correlation, Fisher's $z$ transform was used to convert the correlation values $c$ into $z$, a new variable following a Gaussian distribution:

$$
z=\frac{1}{2} \ln \left(\frac{1+c}{1-c}\right)
$$

From $z$ we can obtain an unbiased estimation of both mean and standard deviation of $c$ (indicated as $\widehat{c}$ and $\sigma c$, respectively):

$$
\begin{aligned}
\widehat{c} & =\tanh (\bar{z}) \\
\sigma c & =\tanh (\sigma z)
\end{aligned}
$$

where $\bar{z}$ and $\sigma z$ are mean and standard deviation of $z$. The compared time series were considered to be significantly related to each other if the non-randomized correlation value did not fall within the band defined by $\widehat{c} \pm 3 \sigma c$. In addition, possible delays between the two time series were tested.

The results of these analyses show that the variation over time of RMS of both the analysed microseismic frequency bands are related to the meteorological parameters (Figures 6, 7). In particular, WTC calculated between seismic RMS and wind speed at both the stations ("Eneide" and "Maria") shows significant relationships at periods longer than 64 hours. The RCC also shows a positive correlation, confirming that the two series are related to each other. As for the delay, RCC provides clearer information, suggesting that the wind speed time series precedes seismic RMS by $5-10$ hours.

As for the sea swells, the results of WTC do not seem reliable, indeed the $5 \%$ significance level areas are mostly in the COI, where the edge effects might distort the picture. This is likely due to the fact that the maximum period, that can be investigated by WTC (about 60 hours), is much shorter than the period range with significant relationships in the case of wind speed (as afore mentioned, longer than 64 hours). Such a difference is related to the different duration of the compared windows ( $\sim 40$ days for wind speed and $\sim 10$ days for sea swell). On the other hand, RCC analysis exhibits a significant positive relationship between the two time series in both the RMS frequency bands.

\subsection{Short duration transients}

The signals of type (iii) are made up of transients with duration of 20-30 s, emergent onset, and frequency content below $2 \mathrm{~Hz}$. In particular, we noted three events characterised by two phases; the second phase shows a slightly lower frequency and a higher amplitude on the horizontal components (Figure 8). On the basis of this, these phases were considered $\mathrm{P}$ and $S$ waves. The spectral analysis highlights that these events show dominant low frequencies, indeed most of their energy is in the band $0.3-1.2 \mathrm{~Hz}$ (Figure 8 $\mathrm{d}, \mathrm{h}, \mathrm{l})$. The similar spectral content and waveform, and the almost equal S-P times of $\sim 16.1 \pm 0.6 \mathrm{~s}$ observed in all the three events, suggest a common source area. Initially, to get an idea of the rough distance of the source area, we made use of the S-P times. We calculated such a distance on the basis of P-wave velocity of $4.5 \mathrm{~km} / \mathrm{s}$ and S-wave velocity of $2.5 \mathrm{~km} / \mathrm{s}$ [Park et al. 2016, and references therein]. The approximated station-source distance was about $93 \mathrm{~km}$. In order to have an idea about the direction of the source area with respect to the stations, the polarization analysis, based on the eigenvalue decomposition of the covariance matrix of the three components of ground motion 
$f<0.25 \mathrm{~Hz}$

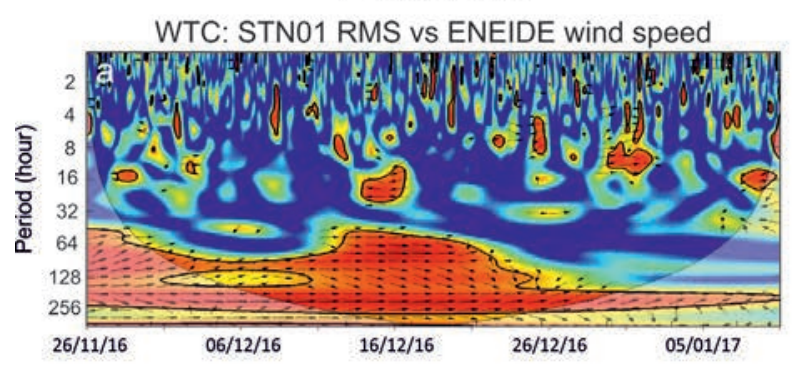

WTC: STN01 RMS vs MARIA wind speed

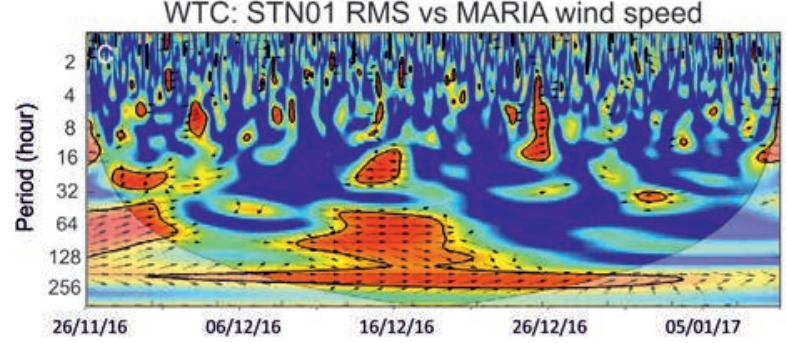

Rand. CCC: STN01 RMS vs ENEIDE wind speed
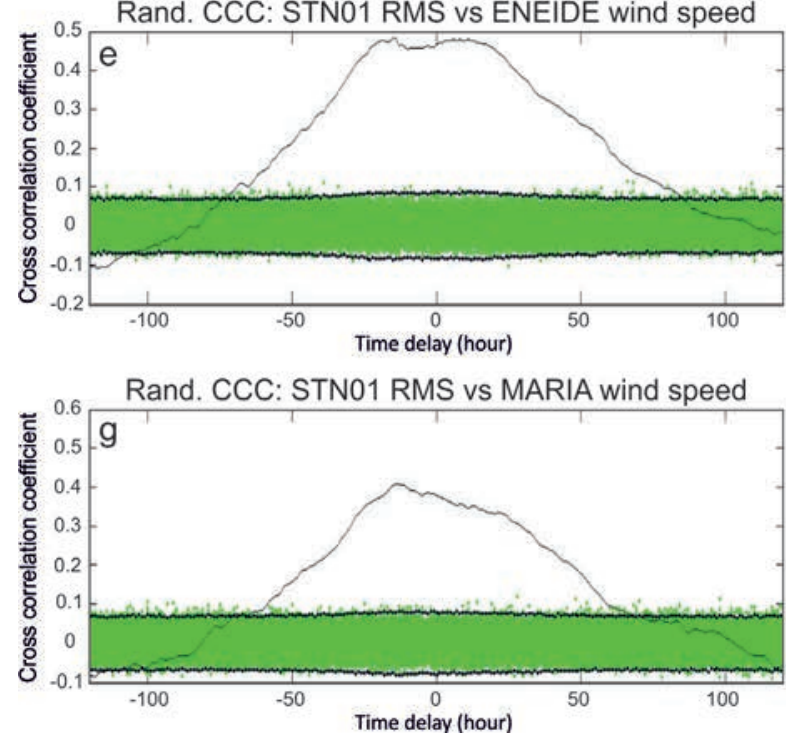

$0.25<f<1.50 \mathrm{~Hz}$

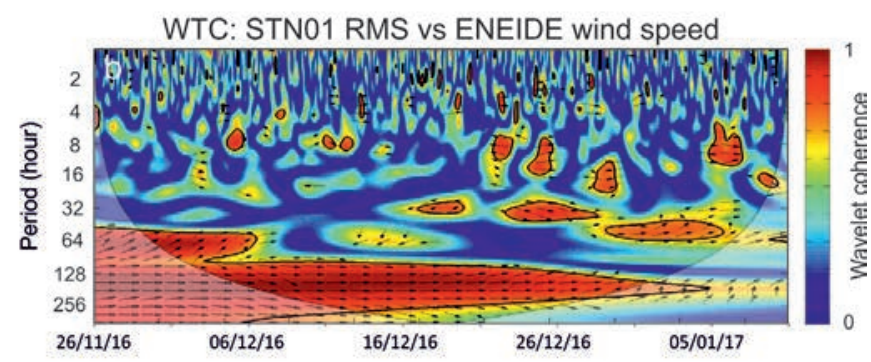

WTC: STN01 RMS vs MARIA wind speed
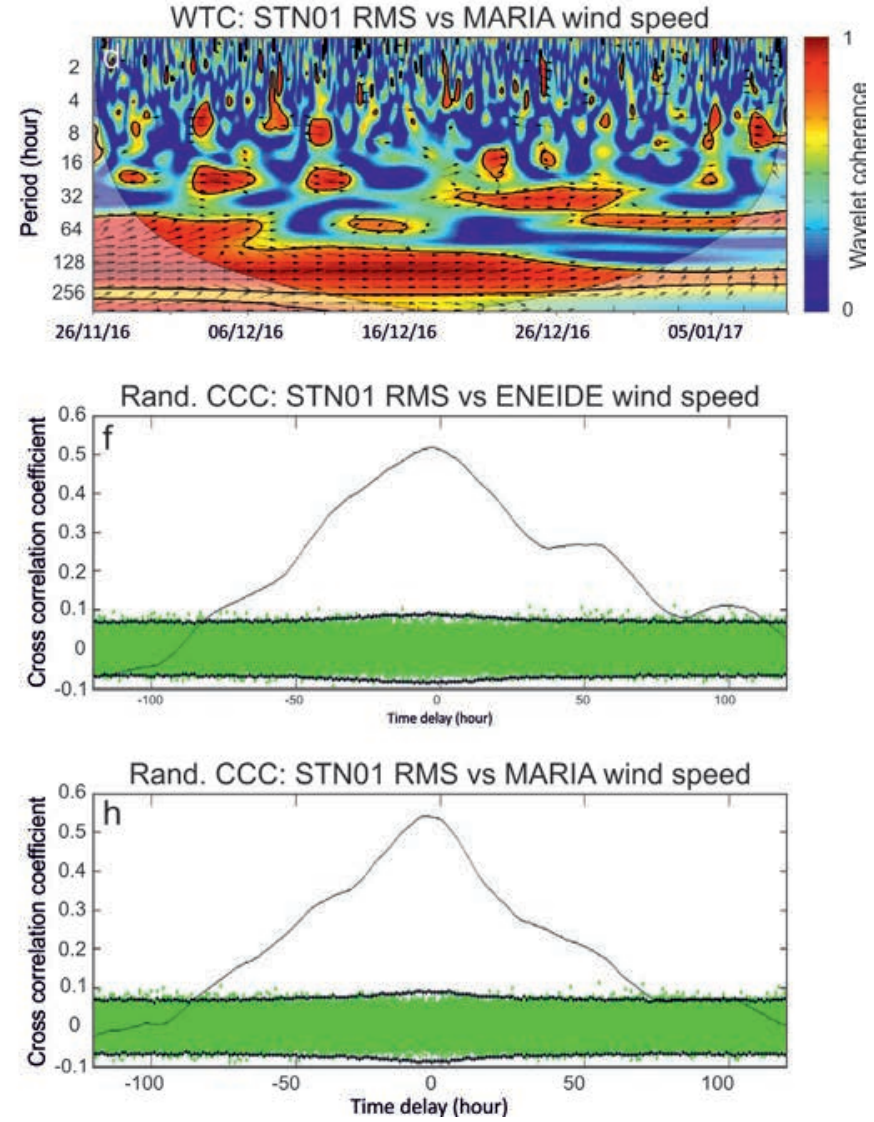

Figure 6. (a-d) WTC performed between seismic RMS, calculated in two bands, and wind speed measured by Maria and Eneide meteorological stations. The $5 \%$ significance level against red noise is shown as a thick contour. The vectors indicate the phase difference between RMS and wind speed (a horizontal arrow pointing from left to right signifies in phase and an arrow pointing vertically upward means the seismic RMS lags wind speed time series by $90^{\circ}$ ). The cone of influence (COI), where the edge effects might distort the picture, is shown with a lighter shade. (e-h) Randomised cross correlation analysis performed between seismic RMS, calculated in two bands, and wind speed measured by Maria and Eneide meteorological stations. Continuous black lines are the cross correlation functions obtained for the original data testing different time lags; green dots are the cross-correlation estimates derived by randomizing the wind speed time series. Dotted black lines mark the $99 \%( \pm 3 \sigma)$ confidence bounds on the distribution of the correlation values obtained at individual time lags. The lags are negative when seismic RMS follows wind speed time series. Wind speed data were provided by 'Meteo-Climatological Observatory' of PNRA (http: / / www.climantartide.it).

[Jurkevics 1988], was performed. In particular, we calculated source azimuth and rectilinearity coefficient within 2-second-long sliding windows. The P-waves are characterised by high values of rectilinearity (mainly above 0.9 ) as well as by source azimuth of about $30-35^{\circ}$ (Figure 9). By merging source azimuth from polarization analysis and source-station distance from S-P differential time, we tried to get an approximated and preliminary source location, which roughly matches the area of the David Glacier - Drygalski Ice Tongue (Figure 10).
Successively, in order to perform classical location analysis, seismic data of STN01 and STN02 were integrated with signals recorded by SBA station (Ross Island) and VNDA station (Wright Valley), available in the Incorporated Research Institutions for Seismology (IRIS; www.iris.edu) seismic database (see image in Figure 11). The sources of the three events were located by HYPOINVERSE-2000 software [Klein 2002] by using the PREM velocity model [Dziewonski and Anderson 1981]. In particular, 2 events (29-November and 

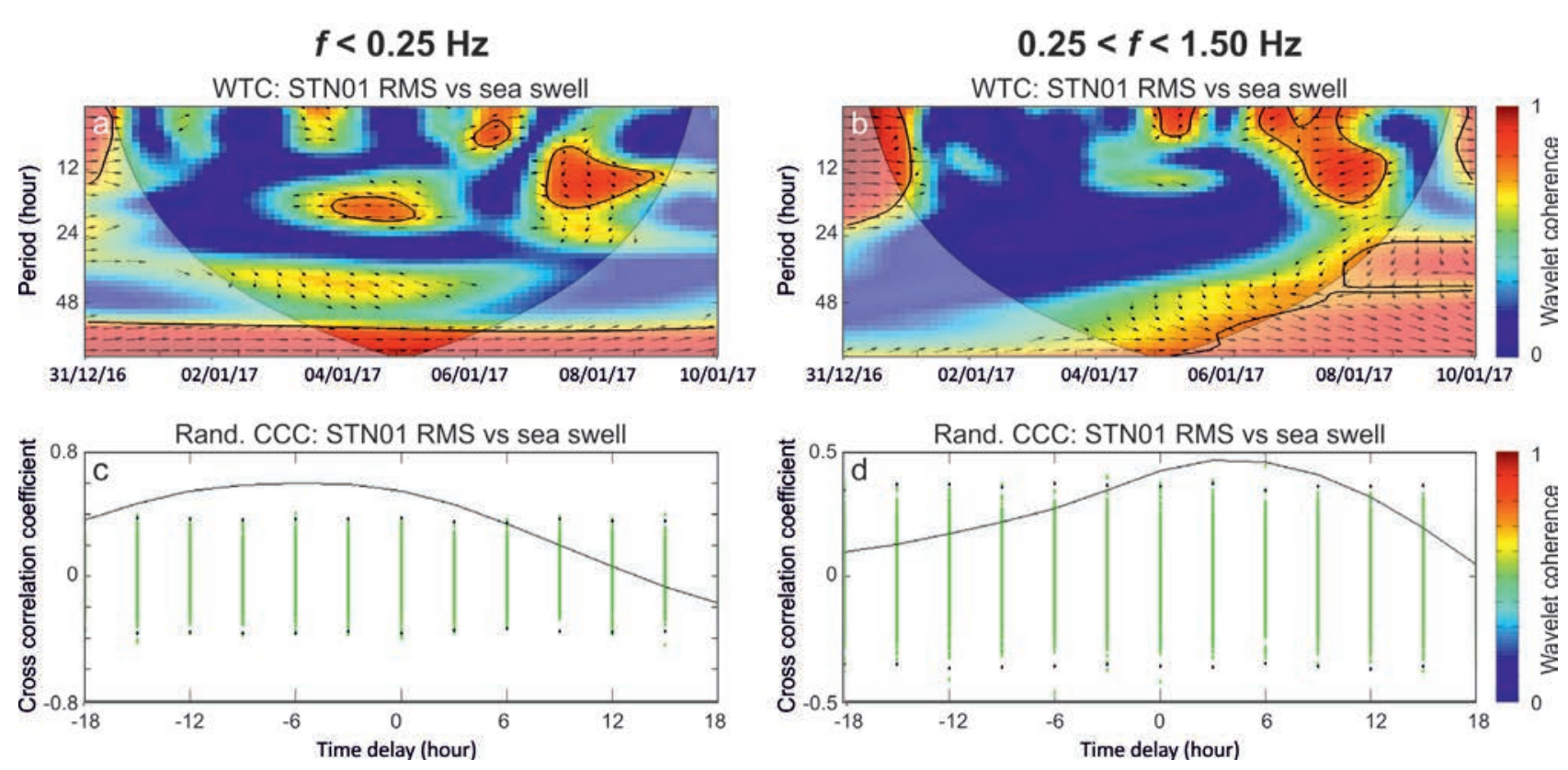

Figure 7. (a-b) WTC performed between seismic RMS, calculated in two bands, and sea swell. The 5\% significance level against red noise is shown as a thick contour. The vectors indicate the phase difference between RMS and sea swell (a horizontal arrow pointing from left to right signifies in phase and an arrow pointing vertically upward means the first series lags the second one by $90^{\circ}$ ). The cone of influence (COI), where the edge effects might distort the picture, is shown as a lighter shade. (c-d) Randomised cross correlation analysis performed between seismic RMS, calculated in two bands, and sea swell. Continuous black lines are the cross correlation functions obtained for the original data testing different time lags; green dots are the cross-correlation estimates derived by randomizing the sea swell time series. Dotted black lines mark the $99 \%( \pm 3 \sigma)$ confidence bounds on the distribution of the correlation values obtained at individual time lags. Sea swell information was provided by Ufficio Meteorologico of MZS.

6-December) were located by 4 stations, while the third one (23-December) by 3 stations because of the lack of SBA signals (see insets in Figure 11). The horizontal and vertical errors are in the ranges $17-19$ and $3-5 \mathrm{~km}$, respectively. Such an analysis confirmed that the event sources were located in the David Glacier area, with focal depth ranging between 2 and $8 \mathrm{~km}$ b.s.l.

On the basis of these locations, these events can likely be considered icequakes. Once the hypocentres were defined, we were able to calculate the local magnitude of the three events that ranged between 2.4 and 2.6.

Finally, following the approach of Danesi et al. [2007] and Baumbach and Bormann [2012], we estimated the source parameters. We calculated the loglog spectra of the displacement P-wave phases for the three events (Figure 12), and estimated the amplitude of the flat part $\left(u_{0}\right)$, as well as the corner frequency $\left(f_{c}\right)$. As also observed by Danesi et al. [2007], we found an excess of energy at low frequencies, that was inferred to be due to propagation in the ice layer, acting as a wave guide for surface waves and playing a role as a filter for high frequencies [e.g. Sgattoni et al. 2016]. In the light of this, to estimate the amplitude of the flat part of the spectra, we did not take frequencies lower than $2 \mathrm{~Hz}$ into account. Under the assumption of a homogeneous Earth model (with density of 2700 $\mathrm{kg} / \mathrm{m}^{3}$ ), constant $\mathrm{P}$ and $\mathrm{S}$ wave velocity (equal to 4.5 $\mathrm{km} / \mathrm{s}$ and $2.5 \mathrm{~km} / \mathrm{s}$; Park et al. 2016, and references therein) and simplified source geometry model, the average value of seismic moment for the three events was $\sim 5.6 \pm 0.4 \cdot 10^{14} \mathrm{Nm}$. In addition, assuming a circular fault source model, source radius, area and average dislocation were estimated equal to $\sim 163 \pm 54 \mathrm{~m}, 8.9 \pm 6 \cdot 10^{4} \mathrm{~m}^{2}$, and $0.44 \pm 0.22 \mathrm{~m}$, respectively. On the other hand, if we assume that the events took place in the ice, seismic velocity and density are different [S-wave velocity $1.95 \mathrm{~km} / \mathrm{s}$, and density $917 \mathrm{~kg} / \mathrm{m}^{3}$; Danesi et al. 2007]. Hence, the seismic moment for the three events was $\sim 8.1 \pm 0.5 \cdot 10^{13}$ $\mathrm{Nm}$, source radius, area and average dislocation were $\sim 122 \pm 40 \mathrm{~m}, 5.0 \pm 3.4 \cdot 10^{4} \mathrm{~m}^{2}$, and $0.60 \pm 0.30 \mathrm{~m}$.

\section{Discussion}

Seismic recordings acquired in Tethys Bay (Victoria Land) during 27 November 2016 - 10 January 2017 allowed recognising a wide variety of signals, such as microseisms, teleseismic earthquakes and icequakes. In this work, we focused on the first and third ones.

As for microseisms, two bands of high amplitude signal were identified $(<0.25 \mathrm{~Hz}$ and $0.25-1.50 \mathrm{~Hz}$; Figure 3) exhibiting similar temporal trends of amplitude variations. It has been shown how microseisms are mostly composed of ocean-generated Rayleigh and 

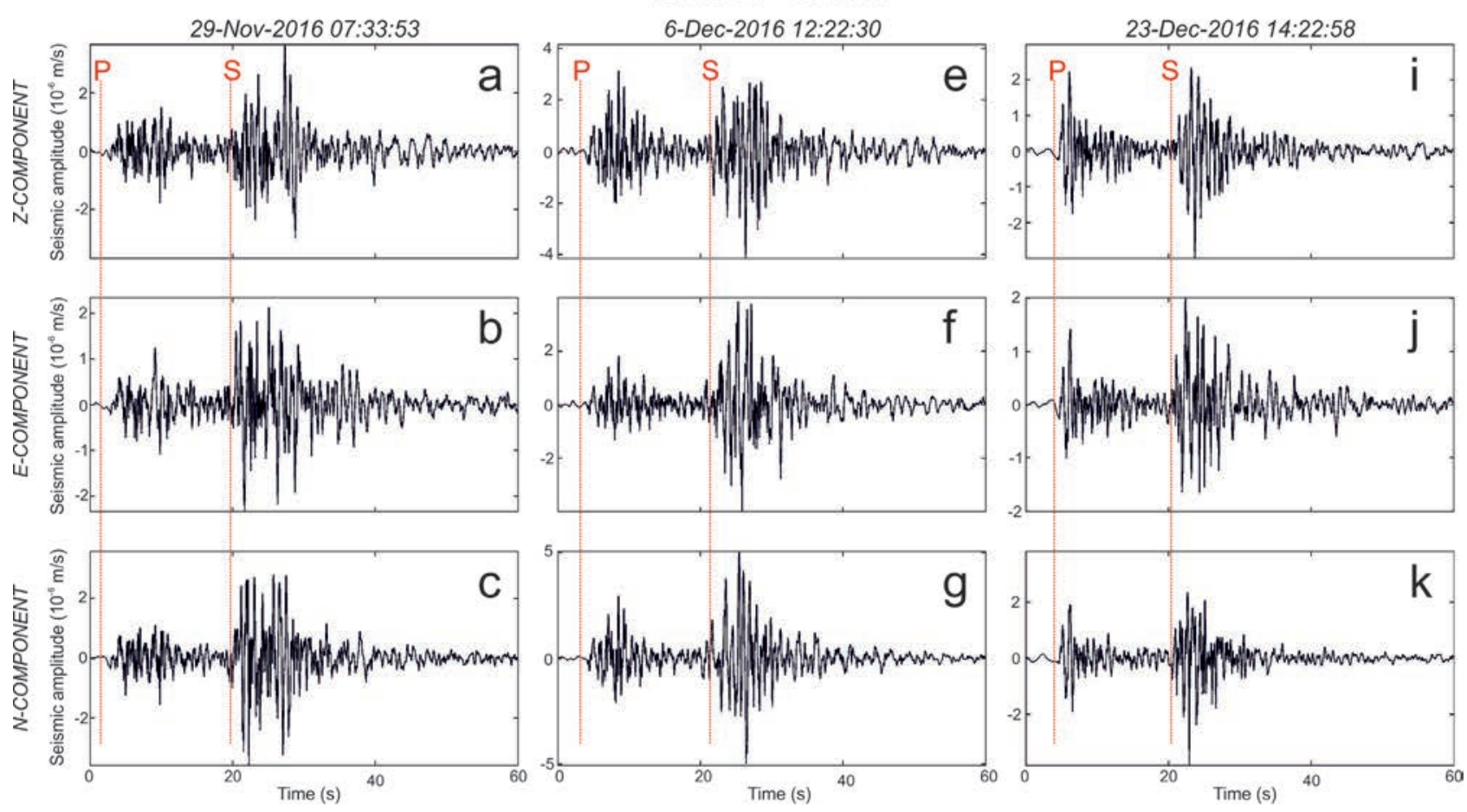

SPECTRA
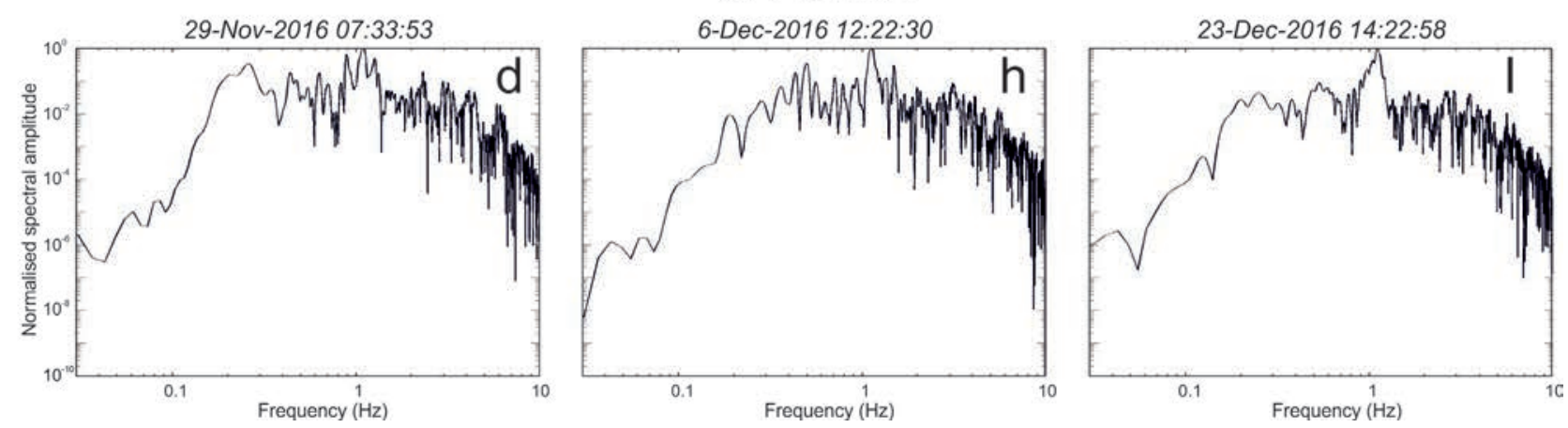

Figure 8. Vertical (a,e,i), E-W (b,f,j), N-S components (c,g,k) of the seismic signals recorded by STN01, and corresponding spectra (d,h,l) of the vertical components.

Love waves [e.g. Pratt et al. 2017]. In addition, Pratt et al. [2017] infer that single-frequency microseisms (13-16 s period) and short-period double frequency microseisms (5-7 s) are generated on the continental shelf and are highly dependent on sea ice concentrations, while long-period double frequency (9-11 s) is excited by storms in the deep ocean. Thus, in order to gain insights into the source of the recorded microseisms, the relationship between the RMS temporal patterns and the changes over time of wind speed (at two stations installed close to Tethys Bay) and sea swell in the coast close to MZS, qualitatively evaluated by the Ufficio Meteorologico of MZS, was investigated (Figures 6,7). A statistically significant relationship was found with a delay of 5-10 hours between wind speed and microseisms; such a delay is in agreement with the values obtained by Duennebier et al. [2012], who compared wind speed and acoustic data recorded by a hydrophone installed in Oahu (Hawaii). These findings suggest that the recorded microseism is caused by waves in shorelines close to the seismic stations, rather than by the generation of seismic energy in the deep ocean under storms. Energetic sources of microseisms were located by Lee et al. [2011] and Pratt et al. [2017] around the coastline of Antarctica, where the continental shelf is ice-free. Evidence of microseisms, caused by waves in shorelines, was obtained by Bromirski and Duennebier [2002] by comparing ambient noise data recorded at the near-coastal ocean bottom and inland seismic stations on the Oregon coast with buoy data. More- 

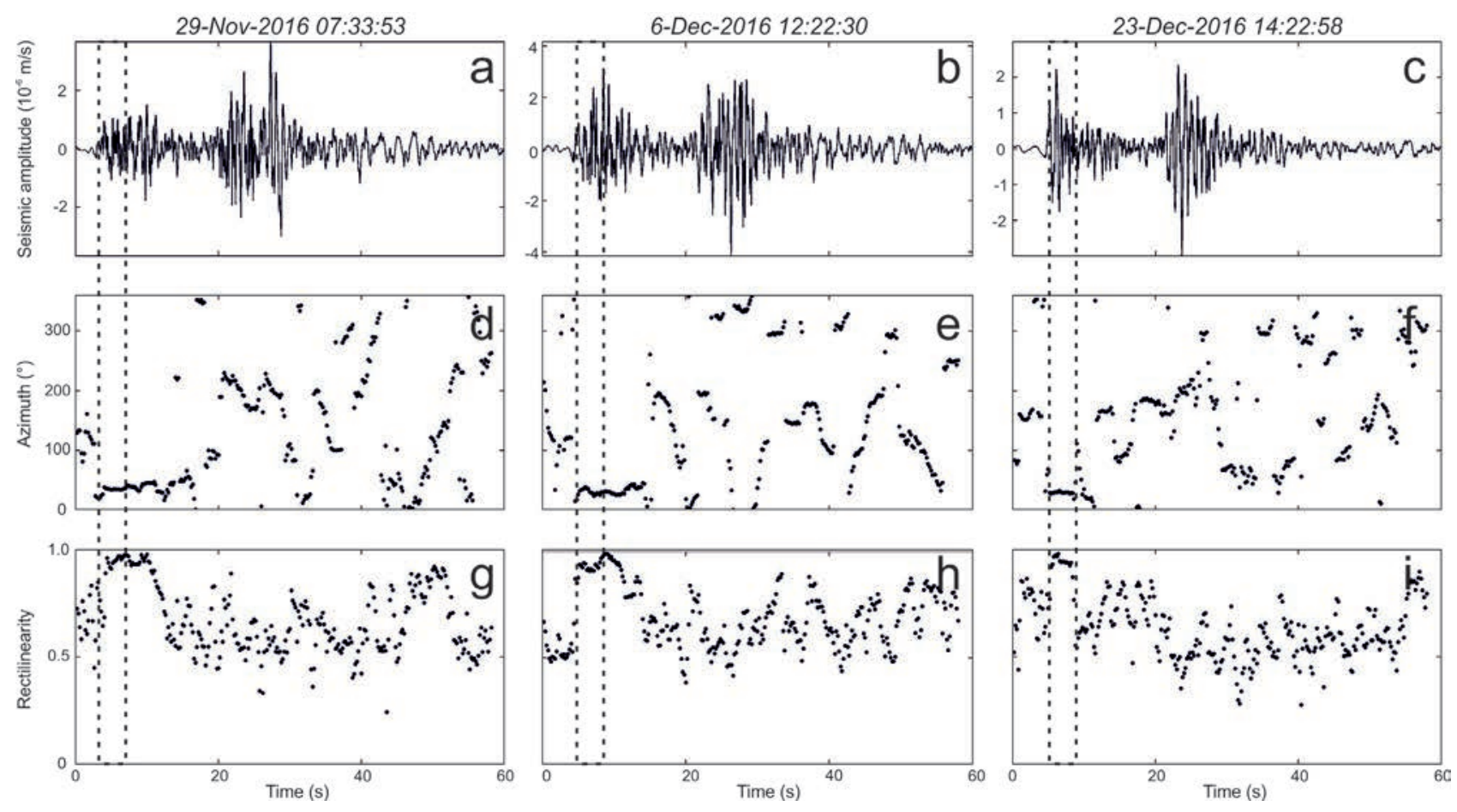

Figure 9. Vertical (a,b,c) component of the seismic signals recorded by STN01, azimuth (d,e,f) and rectilinearity coefficient (g,h,i).

over, in the time series shown in this work, there is no evidence of amplitude modulations dependent on sea ice concentrations over the continental shelf, as highlighted by many authors [e.g. Grob et al. 2011, Pratt et al. 2017]. However, the investigated time interval is probably too short to show such seasonal modulations.

Concerning icequakes, we detected three events (on 29 November, 6 December, 23 December 2016; Figure 8), with dominant low frequencies (below $2 \mathrm{~Hz}$ ), located in the area of David Glacier,

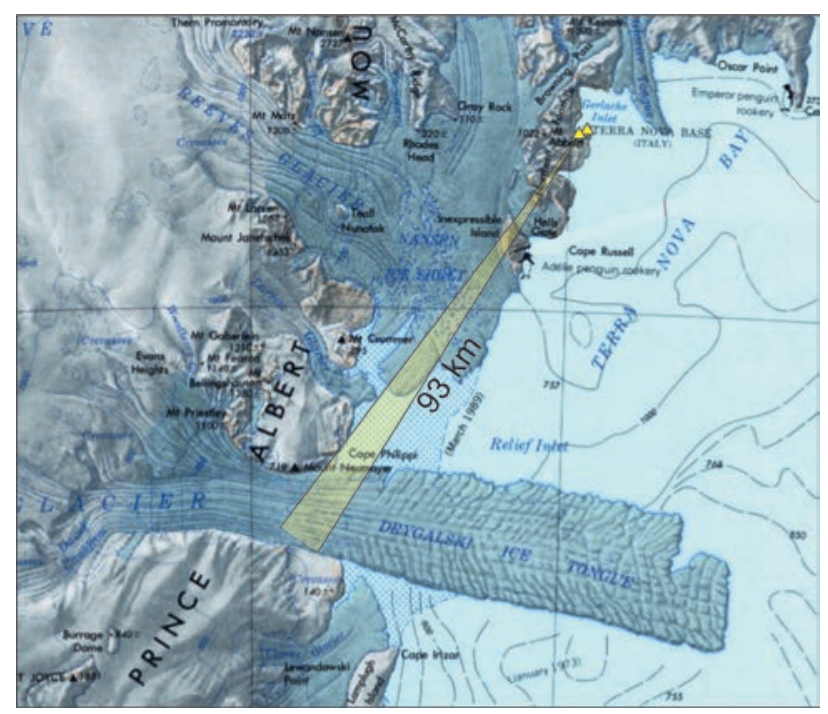

Figure 10. Approximated source location by using the source azimuth (black line and yellow area) and the source-station distance, calculated by the S-P differential times. Yellow triangles represent the two seismic stations STN01 and STN02. one of the major Antarctic glaciers, draining about $4 \%$ of East Antarctica ice [e.g. Rignot 2002, Zoet et al. 2012]. In this area, seismic events, associated with the glacier dynamics, were also detected and investigated by Gambino and Privitera [1994], Danesi et al. [2007] and Zoet et al. [2012]. In particular, by a dense seismic array operating during 20012003, Zoet et al. [2012] identified a huge number of seismic events $(20,000$ events in 9 months) with epicentres in the same portion of the David Glacier as epicentres of the events located in this study (Figure 11). This strong seismic activity, which according to our data continued at least up to the end of 2016, is concentrated near the head of David Glacier, where the ice thickness is $\sim 1.8 \mathrm{~km}$ [Frezzotti et al. 2000], and points to the quick dynamics of the glacier, characterised by an advance rate of $\sim 730 \mathrm{~m}$ $\mathrm{y}^{-1}$ [Wuite et al. 2009]. The low number of events detected in this study during the $\sim 40$-day-long recording period can be due to the long distance of the seismic stations from the sources, permitting to detect only the strongest events. In confirmation of this, Zoet et al. [2012] showed that the stronger the events, the longer the inter-event spacing, and hence the lower the occurrence rate. The source parameters, calculated on the basis of the spectra features, suggest that not only the source location but also the mechanism of the detected icequakes is similar to the source mechanism of the events studied by Danesi et al. [2007] and Zoet et al. [2012]. According to 


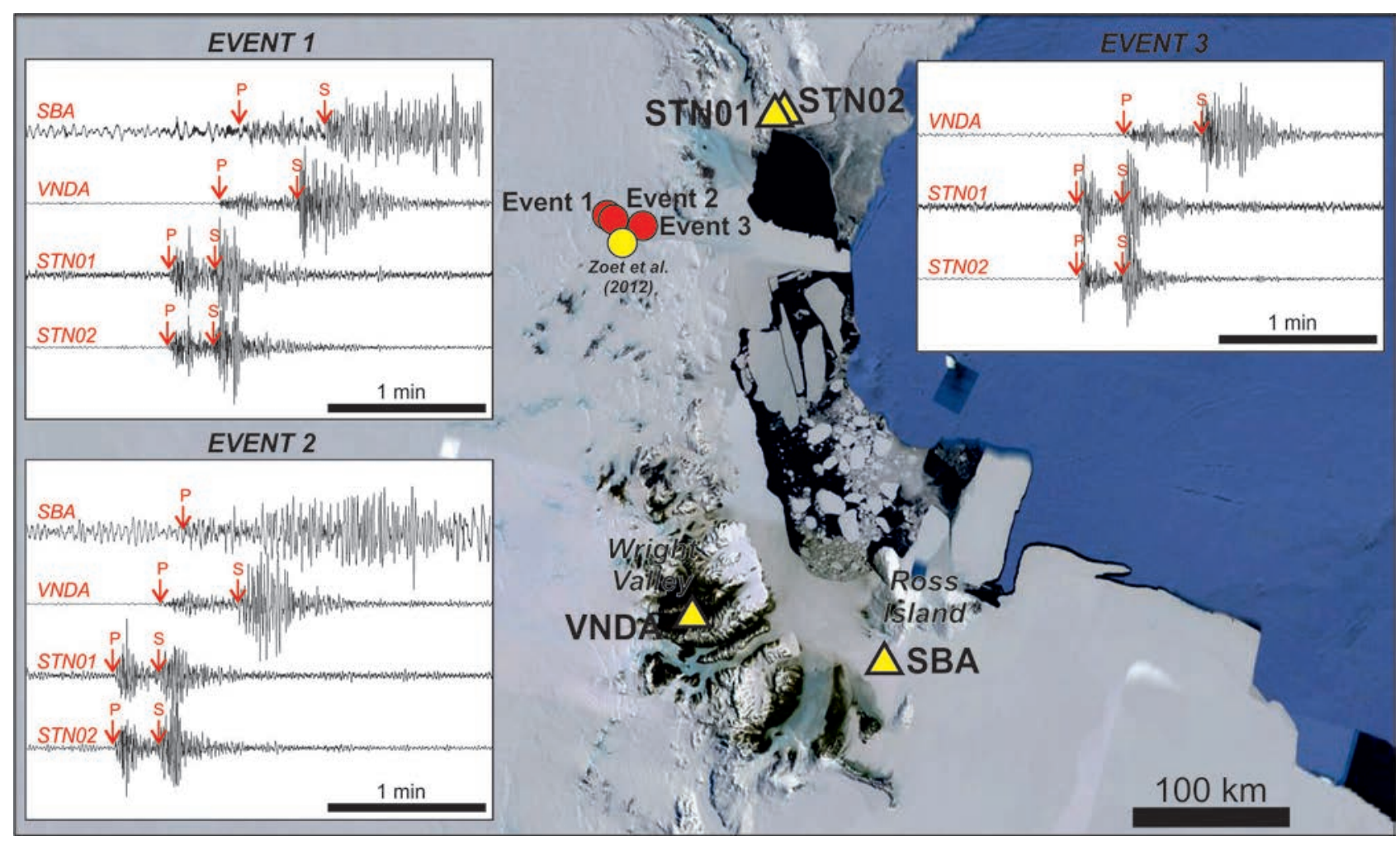

Figure 11. Aerial image from Google Earth, showing the locations of the 4 seismic stations used for the location analysis (yellow triangles), the epicentres of the 3 seismic events analysed in this study (red circles; event 1: 29 November; event 2: 6 December; event 3: 23 December), and the epicentre of the events analysed by Zoet et al. (2012) (yellow circle). The rectangular insets show the vertical component of the seismic events recorded by the stations used for the location analysis, with the corresponding $\mathrm{P}$ and $\mathrm{S}$ wave arrival times (red arrows).

them, these events are likely generated at the rock-ice interface under the glacier. Unfortunately, the calculated wide depth range, as well as the high vertical errors, do not allow confirming that these events take place at such an interface. In light of the inferred source mechanism, the study of these events can provide information about the glacier dynamics, and thus a continuous seismic monitoring could help detect possible variations in time of such a dynamics. Although the seismic monitoring by a local network close to the glacier is desirable, this investigation demonstrates the feasibility of a longrange monitoring of the strongest icequakes produced by the David Glacier. This work shows how seismic signals recorded in Antarctica provide insights into interactions between atmosphere-cryosphere-hydrosphere. Since climate patterns drive these interactions, investigations on Antarctic seismic signals could serve as a proxy indicator for estimating climate changes.
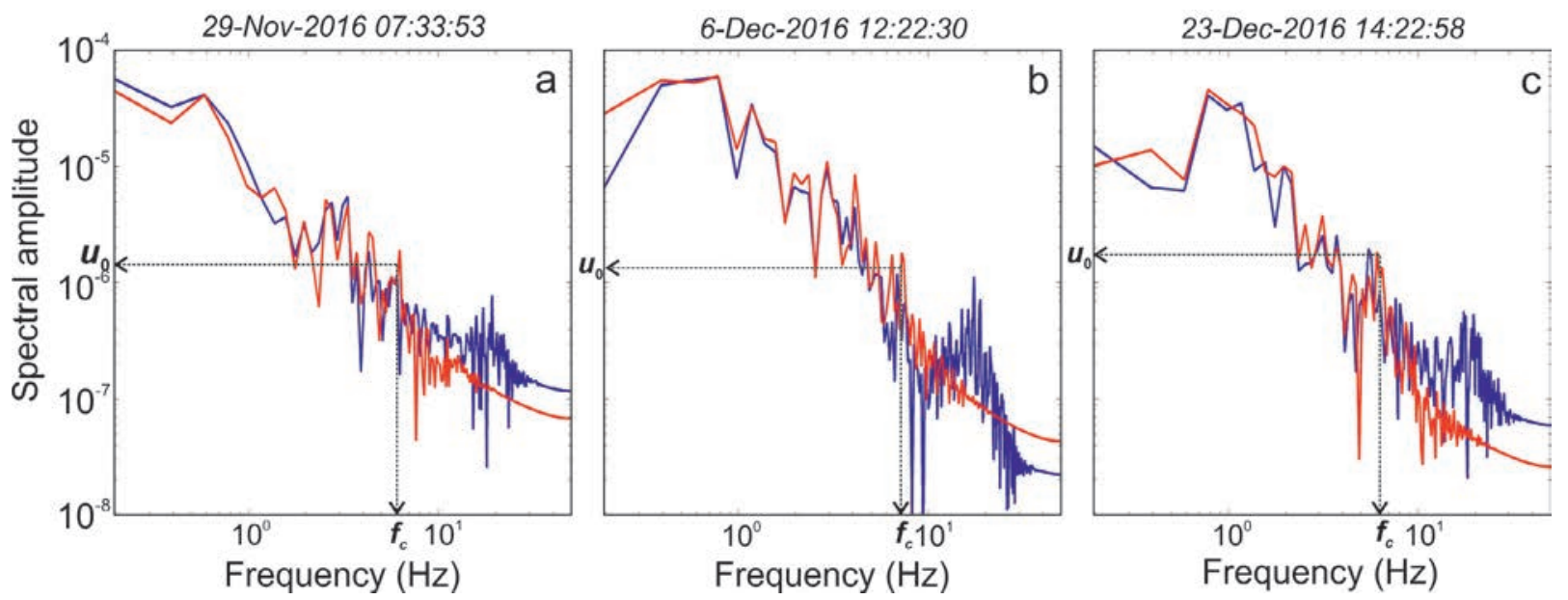

Figure 12. Displacement spectra of the vertical component of the P phases of the three seismic events recorded by STN01 (red line) and STN02 (blue line). $u_{0}$ and $f_{c}$ indicate the amplitude of the flat part and the corner frequency, respectively. 


\section{Data and sharing resources}

The seismic data can be requested from Andrea Cannata (andrea.cannata@unipg.it) or can be downloaded from the project website www.icevolc-project.com. The wind speed data were obtained from 'Meteo-Climatological Observatory' of PNRA - www.climantartide.it.

Acknowledgements. This work was funded by PNRA14_00011 project, called ICE-VOLC ("multiparametrIC Experiment at antarctica VOLCanoes: data from volcano and cryosphere-ocean-atmosphere dynamics", www.icevolc-project.com/data). We acknowledge PNRA (Programma Nazionale di Ricerche in Antartide) for funding the project, ENEA for providing field logistics, and CNR for scientific support. Crosswavelet and wavelet coherence software were kindly provided by A. Grinsted. Data and information about wind speed were obtained from 'Meteo-Climatological Observatory' of PNRA - www.climantartide.it. We kindly acknowledge the Ufficio Meteorologico of MZS (Francesco Sudati and Giuliana D’Ercole) for providing sea swell data. We are grateful to the helicopter pilots Jamie Henery and Bob Mcelhinney and the alpine guide Davide De Podestà. The facilities of IRIS Data Services, and specifically the IRIS Data Management Center, were used for access to waveforms of SBA and VNDA seismic stations. IRIS Data Services are funded through the Seismological Facilities for the Advancement of Geoscience and EarthScope (SAGE) Proposal of the National Science Foundation under Cooperative Agreement EAR-1261681. In particular, we used data from Global Telemetered Seismograph Network (USAF/ USGS). We are grateful to the Editor Francesca Bianco, the Associate Editor, and two anonymous reviewers for their useful suggestions that greatly improved the paper. We thank S. Conway for revising and improving the English text.

\section{References}

Anthony, R. E., R. C. Aster, D. Wiens, A. Nyblade, S. Anandakrishnan, A. Huerta, J. P. Winberry, T. Wilson, and C. Rowe (2015). The seismic noise environment of Antarctica. Seismological Research Letters, 86, 89-100, doi: 10.1785/0220140109.

Aster, R.C., D.E. McNamara and P.D. Bromirski (2008). Multidecadal Climate-induced Variability in Microseisms, Seismological Research Letters, 79, doi: 10.1785 / gssrl.79.2.194.

Baumbach, M. and P. Bormann (2012). Determination of source parameters from seismic spectra, in New Manual of Seismological Observatory Practice, P. Bormann (Editor), GFZ Potsdam.

Beroza, G.C., and S. Ide (2011). Slow Earthquakes and Nonvolcanic Tremor. Annu. Rev. Earth Planet. Sci., 39, 271-296.

Brenguier, F., D. Rivet, A. Obermann, N. Nakata, P. Boué, T. Lecocq, M. Campillo and N. Shapiro (2016). 4-D noise-based seismology at volcanoes: Ongoing efforts and perspectives, J. Volcanol. Geotherm. Res. 321, 182-195, http://dx.doi. org/10.1016/j.jvolgeores.2016.04.036.

Bromirski, P.D. and F.K. Duennebier (2002). The near-coastal microseism spectrum: Spatial and temporal wave climate relationships, Journal of Geophysical Research, 107, B8, 2166, doi:10.1029/ 2001JB000265.

Cannata, A., G. Giudice, S. Gurrieri, P. Montalto, S. Alparone, G. Di Grazia, R. Favara and S. Gresta (2010). Relationship between soil CO2 flux and volcanic tremor at Mt. Etna: implications for magma dynamics, Environ. Earth Sci., 61, 477-489, doi:10.1007/s12665-009-0359-z.

Cannata, A., P. Montalto and D. Patanè (2013). Joint analysis between infrasound and seismic signals by cross wavelet transform: detection of Mt. Etna explosive activity, Natural Hazards and Earth System Sciences, 13, 1-9, doi: 10.5194/nhess-13-1669-2013.

Danesi, S., S. Bannister and A. Morelli (2007). Repeating earthquakes from rupture of an asperity under an Antarctic outlet glacier, Earth Planet. Sci. Lett., 253(1-2), 151-158, doi:10.1016/j.epsl.2006.10.023.

Donner, R. and M. Thiel (2007). Scale-resolved phase coherence analysis of hemispheric sunspot activity: a new look at the north-south asymmetry, Astron. Astrophys., 475, L33-L36, doi:10.1051/00046361:20078672, 2007.

Dziewonski, A. M., and D. L. Anderson (1981). Preliminary reference Earth model. Physics of the Earth and Planetary Interiors, 25, 297-356, doi:10.1016/0031-9201(81)90046-7.

Duennebier, F. K., R. Lukas, E.M. Nosal, J. Aucan and R. A. Weller (2012). Wind, waves, and acoustic background levels at Station ALOHA, J. Geophys. Res., 117, C03017, doi:10.1029/2011JC007267.

Ferretti, G., A. Zunino, D. Scafidi, S. Barani and D. Spallarossa (2013). On microseisms recorded near the Ligurian coast (Italy) and their relationship with sea wave height, Geophys. J. Int., 194, 524-533.

Frezzotti, M., I. Tabacco, and A. Zirizzotti (2000). Ice discharge of eastern Dome $\mathrm{C}$ drainage area, Antarctica, determined from airborne radar survey and satellite image analysis. J. Glaciol., 46, 253-264.

Gambino, S. and E. Privitera (1994). Characterization of Earthquakes Recorded by Mt. Melbourne Volcano Seismic Network (Northern Victoria Land, Antarctica), Terra Antarctica, 1, 167-172.

Grevemeyer, I., R. Herber and H. Essen (2000). Microseismological evidence for a changing wave climate in the northeast Atlantic Ocean, Nature, 408, 349-352.

Grinsted A., J.C. Moore and S. Jevrejeva (2004). Application of the cross wavelet transform and wavelet coherence to geophysical time series, Nonlinear Process Geophys, 11, 561-566. 
Grob, M., A. Maggi and E. Stutzmann (2011). Observations of the seasonality of the Antarctic microseismic signal, and its association to sea ice variability, Geophys. Res. Lett., 38, L11302, doi:10.1029/2011GL047525.

Hasselmann, K. (1963). A statistical analysis of the generation of microseisms, Rev. geophys. Space Phys., 1, 177-210.

Jevrejeva, S., J.C. Moore and A. Grinsted, A. (2003). Influence of the Arctic Oscillation and $\mathrm{El} \mathrm{Ni}$ no-Southern Oscillation (ENSO) on ice conditions in the Baltic Sea: the wavelet approach, J. Geophys. Res., 108, 4677, doi:10.1029/2003JD003417.

Jurkevics, A. (1988). Polarization analysis of three-component array data, Bull. Seismol. Soc. Am 78, 1725-1743.

Klein, F.W. (2002). User's Guide to HYPOINVERSE-2000, a Fortran Program to Solve for Earthquake Locations and Magnitudes. U.S. Geological Survey Open-File Report 02-171, 123 pp.

Lee, W.S., D.H. Sheen, S. Yun and K.W. Seo (2011). The origin of double-frequency microseism and its seasonal variability at King Sejong Station, Antarctica. Bulletin of the Seismological Society of America, 101, 1446-1451. doi:10.1785/20100143.

Martini, F., C. J. Bean, G. Saccorotti, F. Viveiros and N. Wallenstein (2009). Seasonal cycles of seismic velocity variations detected using coda wave interferometry at Fogo volcano, São Miguel, Azores, during 2003-2004, J. Volcanol. Geotherm. Res., 181, 231-246.

McNutt, S.R. (2005). Volcanic seismology, Annu. Rev. Earth Planet. Sci., 32, 461-491.

Park, Y., H.J. Yoo, W. Sang Lee, C.K. Lee, J. Lee, H. Park, J. Kim and Y. Kim (2016). P-wave velocity structure beneath Mt. Melbourne in northern Victoria Land, Antarctica: Evidence of partial melting and volcanic magma sources, Earth and Planetary Science Letters, 432, 293-299.

Podolskiy, E.A. and F. Walter (2016). Cryoseismology, Rev. Geophys., 54, doi:10.1002/2016RG000526.

Pratt, M.J., D.A. Wiens, J.P. Winberry, S. Anandakrishnan, and G.G. Euler (2017). Implications of Sea Ice on Southern Ocean Microseisms Detected by a Seismic Array in West Antarctica. Geophysical Journal International, 209, 492-507, doi: 10.1093/ gji/ggx007.

Rignot, E. (2002). Mass balance of East Antarctic glaciers and ice shelves from satellite data, Ann. Glaciol. 34, 217227.

Saccorotti, G. and E. Del Pezzo (2000). A probabilistic approach to the inversion of data from a seismic array and its application to volcanic signals, Geophys. J. Int., 143, 249-261.

Sgattoni, G., Z. Jeddi, O. Gudmundsson, P. Einarsson, A. Tryggvason, B. Lund, and F. Lucchi (2016). Long-period seismic events with strikingly regular temporal patterns on Katla volcano's south flank (Iceland). Journal of Volcanology and Geothermal Research, 324, 28-40, doi: 10.1016/j.jvolgeores.2016.05.017.

Torrence, C. and G.P. Compo (1998). A practical guide to Wavelet Analysis, B. Am. Meteorol. Soc., 79, 61-78.

Wuite, J., K. C. Jezek, X. Wu, K. Farness, and R. Carande (2009). The velocity field and flow regime of David Glacier and Drygalski Ice Tongue, Antarctica. Polar Geography, 32, 111-127, doi:10.1080/10889370902815499.

Yang, L., C.M. Wong, E.H.Y. Lau, K.P. Chan, C.Q. Ou and J.S.M. Peiris (2008). Synchrony of Clinical and Laboratory Surveillance for Influenza in Hong Kong, PLoS ONE, 3, e1399, doi:10.1371/journal. pone.0001399.

Zoet, L. K., S. Anandakrishnan, R.B. Alley, A.A. Nyblade and D.A. Wiens (2012). Motion of an Antarctic glacier by repeated tidally modulated earthquakes, Nat. Geosci., 5(9), 623-626.

Zuccarello, L., M. R. Burton, G. Saccorotti, C. J. Bean and D. Patanè (2013). The coupling between very long period seismic events, volcanic tremor, and degassing rates at Mount Etna volcano, J. Geophys. Res. Solid Earth, 118, 4910-4921, doi:10.1002/ jgrb.50363.

\footnotetext{
*Corresponding author: Andrea Cannata, Università degli Studi di Perugia, Dipartimento di Fisica e Geologia, Perugia, Italy; email: andrea.cannata@unipg.it

2017 by Istituto Nazionale di Geofisica e Vulcanologia.

All rights reserved
} 